\title{
Statistical Analysis on the Quality of China's Key Services in 2014
}

\author{
Cai Hualia ${ }^{*}$, J iang Yaweib, Song Heliang c \\ Quality Management Branch, China National Institute of Standardization, Beijing. China \\ a 583451349@qq.com, ${ }^{\mathrm{b}}$ 352362986@qq.com, ${ }^{\mathrm{c}}$ 3833071@qq.com
}

Keywords: key services, quality situation, customer satisfaction

Abstract. With the rapid growth of China's service industries, the supporting role of quality has become increasingly prominent. With a view to mastering the quality situation of service industries in a dynamic way and promoting high-quality efficient and sustainable development, the author makes a statistical analysis on the quality of China's key services in 2014 in terms of customer satisfaction, brand growth and other dimensions.

\section{Introduction}

Analysis was made to the monitoring results of customers' satisfaction towards the State Bureau of the People's Republic of China ${ }^{[1]}$, China National Institute of Standardization, China Tourism Academy ${ }^{[2]}$ and China Banking Association ${ }^{[3]}$, etc. It was discovered from the analysis that the quality of China's services took on a steadily increasing trend and was rated as "Relatively satisfied".

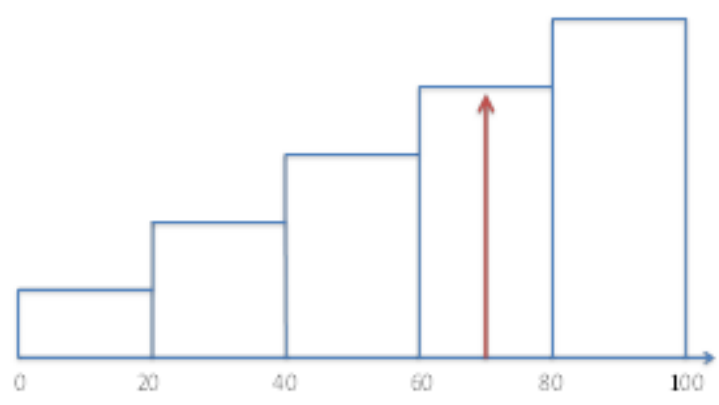

Fig. 1 Customer Satisfaction Ratings

\begin{tabular}{|c|}
\hline Dissatisfied \\
\hline Relatively dissatisfied \\
\hline Average \\
\hline Relatively satisfied \\
\hline Satisfied \\
\hline $\begin{array}{c}\text { Customer satisfaction (in } \\
\text { points) }\end{array}$ \\
\hline
\end{tabular}

The Customer satisfaction evaluation model struture is shown as follows: 


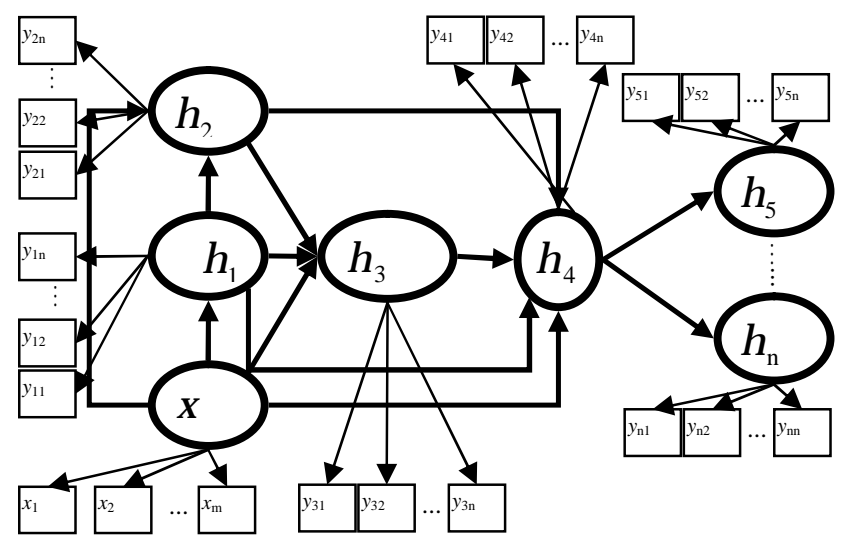

Fig. 2 Example of Customer Satisaction Evaluation Model

Where, cirles indicate latent variables; the arrows between circles indicate the causal relationship among latent variables; rectangles indicate observable variables; and the arrows between rectangles and circles indicate the observable variable-latent variable response relationship.

The example of mathematical form for structural equation is shown as follows:

$$
\eta=\mathrm{B} \eta+\Gamma \xi+\zeta
$$

Where, $\eta$ means endogenous latent variable; $\xi$ means exogenous latent variable; B means relationship between endogenous latent variables; $\Gamma$ means impact of exogenous latent variable on endogenous latent variable; and $\zeta$ means residual of structural equation, which reflects the parts that are unable to be interpreted in equation and subject to independent normal distribution with average value being zero.

The example of mathematical form measuring the equation is shown as follows:

$$
\begin{aligned}
& \mathrm{X}=\Lambda_{x} \xi+\delta \\
& \mathrm{Y}=\Lambda_{y} \eta+\varepsilon
\end{aligned}
$$

Where, $\mathrm{X}$ means the vector formed by exogenous indexes; $\mathrm{Y}$ means the vector formed by endogenous indexes; $\Lambda_{x}$ means the relationship between exogenous and endogenous indexes, or factor loading matrix of exogenous index on exogenous latent variable; $\Lambda_{y}$ means the relationship between endogenous index and endogenous latent variable or factor loading matrix of endogenous index on endogenous latent variable.

The customer satisfaction in life service industry gradually increased on average. Compared on a year-on-year basis, customer satisfaction level was 3.5 up at gas stations (75.29), 2.74 up at express hotels (74.26) and 0.78 down in tourism segment (74.10). However, the average level of customer satisfaction in the production service industry slightly decreased. Customer satisfaction level was 4.49 down in terms of mobile communication (71.08), 0.38 down in terms of online shopping (75.86), $1 \mathrm{up}$ in terms of express delivery (73.70), 1 up in terms of automobile after-sales service (79.00), 1.21 up in terms of automobile insurance (75.65) and 4.63 up at banking segment (76.93) compared to the same period in the previous year. Additionally, monitoring was conducted on online video and news for the first time in 2014, with customer satisfaction level being 74.33 and 76.58 . 


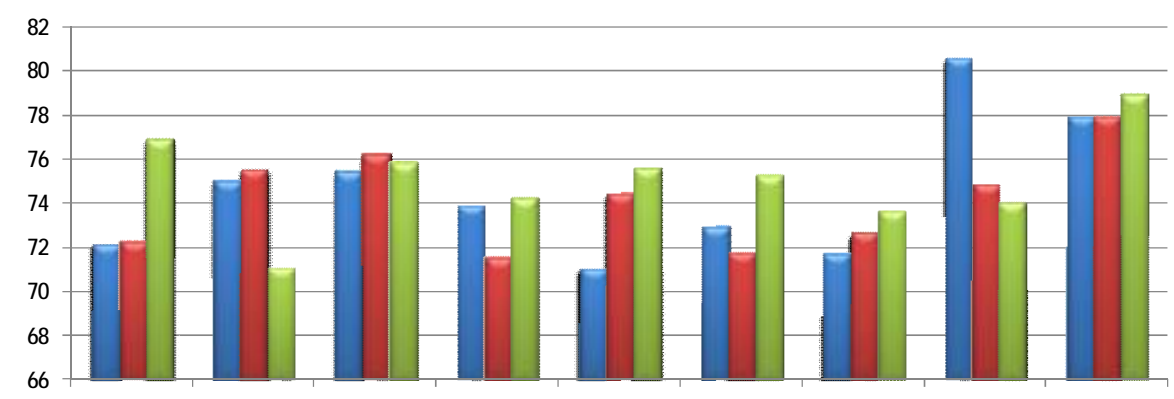

Fig. 3 Monitoring Result of Customer Satisfaction in Service Industries

\begin{tabular}{|l|}
\hline 2012 \\
\hline 2013 \\
\hline 2014 \\
\hline Customer satisfaction level \\
\hline Banking \\
\hline Mobile communication \\
\hline Online shopping \\
\hline Express hotel \\
\hline Automobile insurance \\
\hline Gas station \\
\hline Express delivery \\
\hline Tourism \\
\hline Automobile after-sales service \\
\hline Industry \\
\hline
\end{tabular}

The public service quality situation in ten cities of China, including Hangzhou, Dongying, Suzhou, Wenzhou, Luzhou, Xinxiang, Tongling, Hebi, Yibin and Liuzhou, is analyzed as follows: in terms of segments, public utilities (water, electricity and gas supply) ranked top with the greatest customer satisfaction (86.73), followed by retail and department stores (84.30), public transportation (83.39), education (82.85), food and beverage (80.06), and medical treatment (76.22). Where, the customer satisfaction slightly increased by 0.39 and 0.35 ; medical treatment, education, food and beverage, and public utilities decreased by $2.33,0.77,0.46$ and 0.39 respectively compared to the same period in the previous year.

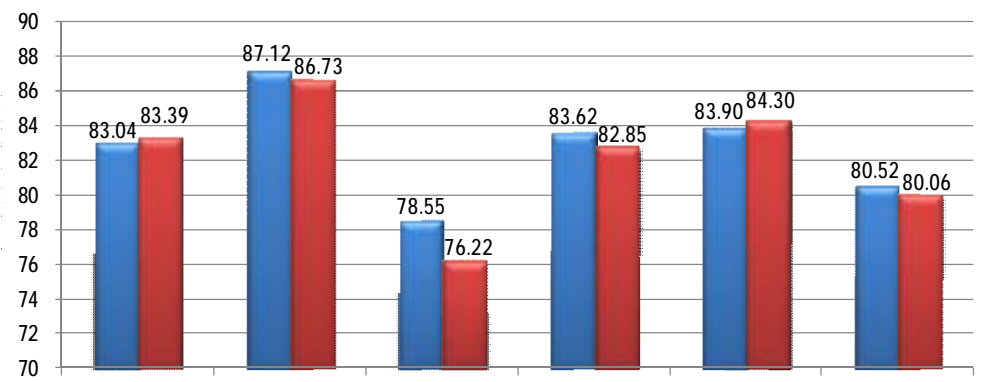

Fig. 4 Monitoring Result of Urban Public Service Quality Satisfaction

\begin{tabular}{|l|}
\hline 2013 \\
\hline 2014 \\
\hline Customer satisfaction level \\
\hline Public transportation \\
\hline Public utilities \\
\hline Medical treatment \\
\hline Education \\
\hline Retail and department stores \\
\hline Food and beverage \\
\hline Segment \\
\hline
\end{tabular}




\section{Issues}

(I) Overall Chinese quality standards should be urgently improved. According to the target set in the Outline of Quality Development (2011-2020), the customer satisfaction in production service industry in 2015 is expected to reach 80 or above and that in living service industry 75 or above. Seen from the 11 industries monitored in 2014, only gas stations just exceeded expected target (75) and the other 10 industries failed to reach such target, with a large gap in mobile communication and express delivery. From an international perspective, in contrast to the United States, the average customer satisfaction was 2.23 lower in China's service industry, 6.04 lower in terms of online shopping, 4.92 lower in terms of mobile communication, 0.74 lower in terms of express hotel. Low customer satisfaction does not only harm the healthy development of China's service industries but also influence the competitiveness of these industries and service trade development. Also, the development of service industries is faced with huge transformation and upgrading pressure. The development mode with capacity increase and expansion as focus should be urgently transformed. And China will undertake arduous tasks in adjusting and optimizing stock and improving quality efficiency.

(II) Brand effect should be enhanced. According to the "Top 100 Most Valuable Global Brands in 2014" published by BrandZ, an international brand value evaluation institution, 9 Chinese service industry brands were listed, namely Tencent, China Mobile, Industrial and Commercial Bank of China (ICBC), Baidu, China Construction Bank (CCB), Agricultural Bank of China (ABC), Bank of China (BOC), Ping'an Insurance and China Life Insurance. The average value of Chinese listed brands totaled $\$ 257.238$ billion, $11.31 \%$ up on a year-on-year basis, and accounted for $8.98 \%$ of the total value of the top 100 brands, $0.72 \%$ down on a year-on-year basis. Tencent, Baidu and other internet brands witnessed a rapid increase in brand value, to $97 \%$ and $46 \%$ respectively while traditional competitive areas including finance and telecommunication experienced a negative increase $(-3.85 \%)$. And the average increase in the brand value of top 100 enterprises was $17 \%$. Ping' an Insurance and ICBC witnessed an increase of $18 \%$ and 2\%; BOC remained unchanged and China Life Insurance, China Mobile, $\mathrm{ABC}$ and $\mathrm{CCB}$ experienced a negative increase, namely $-21 \%$, $-10 \%,-9 \%$ and $-7 \%$. When the service industries continuously expand and becomes the leading industries in China, how to enable "China's service industries" to "become larger and stronger, and even stronger" would directly influence the quality efficiency and sustainability of industry development.

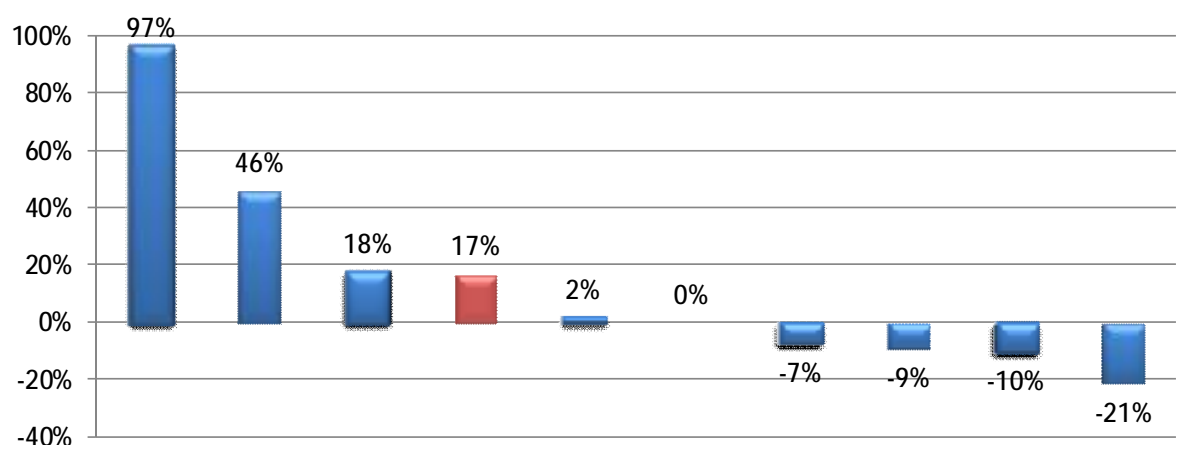

Fig. 5 Service Brand Value Increase in 2014

\begin{tabular}{|l|}
\hline Brand value increase \\
\hline Tencent \\
\hline Baidu \\
\hline Ping'an Insurance \\
\hline $\begin{array}{l}\text { Average level of top } 100 \\
\text { enterprises listed }\end{array}$ \\
\hline ICBC \\
\hline BOC \\
\hline CCB \\
\hline ABC \\
\hline
\end{tabular}




\section{Analysis}

The above issues occurring to service industries have relation to the service industries' characters of focusing on small and medium enterprises and to the rapidly expanded primary development stage. Also, those issues prove incomplete quality governance system of China's service industries and insecure quality foundation of service industry development. Seen from the developed countries and regions in terms of service, the EU formulated regulations on service quality in its Services Directive; Both EU and the USA established the unions of service self-discipline; high-quality service marking system was implemented in Singapore and Hong Kong. Also, the quarterly quality release system has been built for 20 years in the USA, covering 33 major industries, and the standard certification is becoming popular in service industry. However, the quality coordination mechanism of China's service industries remained incomplete. Some areas are characterized by lack of law enforcement basis, sufficient national standards and incomplete coverage of certification (Until the end of 2014, there were only 1,466 service certificates, which relate to 815 enterprises, $0.16 \%$ and $0.19 \%$ of voluntary certification). And service industry quality monitoring covers only 11 areas including tourism, express delivery, banking, gas station, mobile communication and express hotel. It seems hard to fully master the situation of the industry quality.

\section{Acknowledgement}

This work was funded by the Dean fund project of China National Institute of Standardization under grant No. 642015Y-4009, the National Key Technology R\&D Program of the Ministry of Science and Technology under grant No. 2013BAK04B02 and 2013BAK04B04.

\section{REFERENCES}

[1] Notice of the State Post Bureau of the People's Republic of China on Survey Result of Express Delivery Service Satisfaction in 2014. http://www.spb.gov.cn/dtxx 15079/201501/t20150126 414192.html

[2] Research on Survey Report of Chinese Tourists' Satisfaction in Q4 2014 and 2014. http://www.ctaweb.org/html/2015-1/2015-1-9-14-14-46221.html

[3] Yang Zaiping, Executive Vice President of CBA Issued the Report on China's Banking Service Improvement in 2014. http://www.china-cba.net/do/bencandy.php?fid=43\&id=13803 